\title{
Computer-aided design and loaded tooth contact analyses of bevel gear pair having straight teeth by different loaded torques
}

\author{
Sándor Bodzás* \\ Department of Mechanical Engineering, University of Debrecen, Debrecen, Hungary
}

Received: 8 May 2019 / Accepted: 24 October 2019

\begin{abstract}
The aim of this publication is to show how to integrate the designing process of straight bevel gears into a computer software so it can be further used for making the three-dimensional (CAD) model of the gear pair. During meshing the driven and the driving gears engage gradually so contact points can be mathematically determined between the element pairs according to the developed coordinate system's arrangement. With mydeveloped computer software, I designed a certain bevel gear pair having straight teeth. Naturally, many different types of this pair could be designed. After that Loaded Tooth Contact Analysis (LTCA) have been done - by normal stress, normal deformation and normal elastic strain parameters. The aim of the LTCA is the analysis of the connection tooth zone in mechanical aspects by different loads. If the received parameters are not appropriate, you can return to the mechanical designing process where the starting parameters of the gear could be modified. Different load torques were used to determine the established mechanical parameters of the elements.
\end{abstract}

Keywords: Bevel gear / module / LTCA / CAD / normal

\section{Introduction}

Straight bevel gears are applied widely in machinery (in vehicles, tool machines, for medical tools and machines etc.). They are used to connect shafts whose axes intersect in some angles, thus the meshing surfaces form a cone on which teeth are shaped (Fig. 1) [1-6].

One of the oldest process for producing gears applied even today is the Reinecker - Bilgram process. In this case, the vertical shaft of the machine intersects the centre of the pitch surface. The cutting tool makes an alternating movement while the operating pitch cone of the bevel gear unwinds the axoid of the deriving pitch cone (Fig. 2) [1,3-8].

During another production process of HeidenreichHarbeck, the machine uses 2 cutting tools. This method is more advantageous because in this case the machine is moved in the axes perpendicular to the axes of the pitch surface. The machine is not set according to the $\lambda$ dedendum angle, and the grip of the tool is stricter (Fig. 3) [1,3-8].

The paths of the cutting tools are not parallel during production, but they intersect in $2 \cdot \theta$ angle, this is called planing angle, which can be calculated in the following way

\footnotetext{
* e-mail: bodzassandor@eng.unideb.hu
}

[5] (Fig. 4):

$$
\operatorname{arc} \theta=\frac{0.25 \cdot m \cdot \pi+R_{e} \cdot \sin \lambda \cdot \tan \alpha_{0}}{R_{e} \cdot \cos \lambda}
$$

\section{Defining the contact points}

The profile curve $\overrightarrow{r_{1 R}}$ of the bevel gear wheel is made as a result of the movement of the machining tool and the unwinding movement for the $\mathrm{K}_{1 \mathrm{R}}\left(\mathrm{x}_{1 \mathrm{R}}, \mathrm{y}_{1 \mathrm{R}}, \mathrm{z}_{1 \mathrm{R}}\right)$ rotating coordinate system related to the driver gear wheel.

I am looking for the surface connected to $K_{2 R}$ coordinate system related to $\overrightarrow{r_{1 R}}$. I use the fact that the 2 surfaces during their movements coincide. Taking into consideration the following correlation $[4,9]$ :

$$
\varphi_{2 R}=i_{21} \cdot \varphi_{1 R}
$$

I can state that the movement can be described with $\left(\varphi_{1}\right)$ movement parameter $[4,9,10]$.

The relative velocity between the 2 surfaces can be determined by the transformation between the rotating $\mathrm{K}_{1 \mathrm{R}}$ coordinate system of the driver wheel and the rotating $\mathrm{K}_{2 \mathrm{R}}$ coordinate system of the driven wheel $[4,9]$ :

$$
{\overrightarrow{v_{2 R}}}^{(12)}=\frac{d}{d t} \overrightarrow{r_{2 R}}=\frac{d}{d t}\left(\boldsymbol{M}_{2 \boldsymbol{R}, \mathbf{1} \boldsymbol{R}}\right) \cdot \overrightarrow{r_{1 R}} .
$$




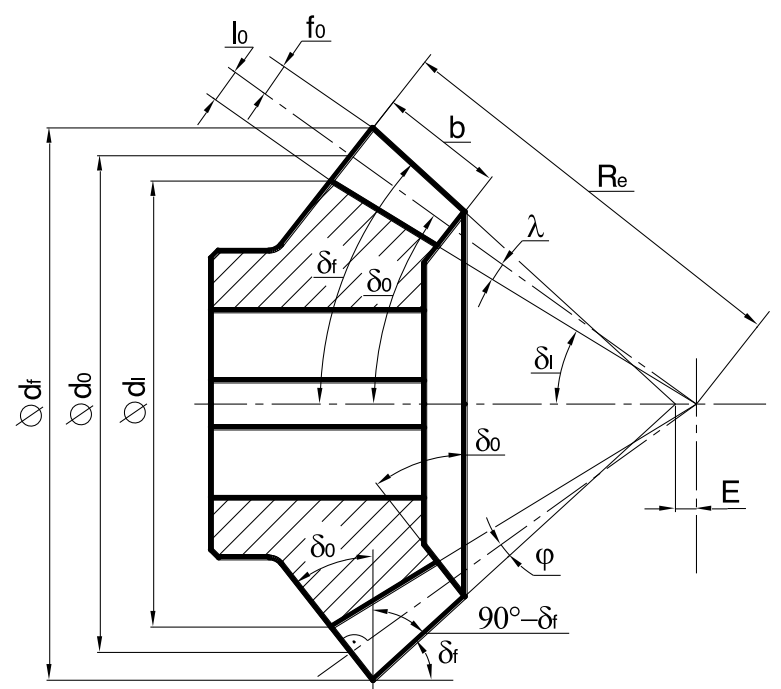

Fig. 1. Angles and diameters of bevel gear.

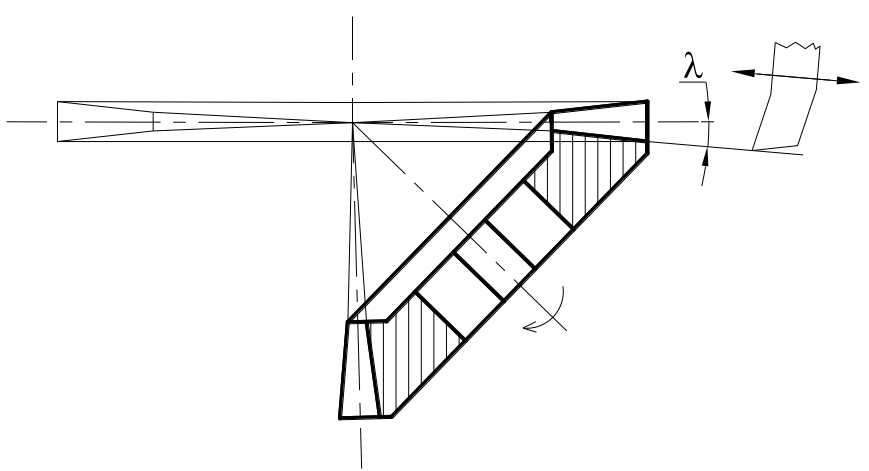

Fig. 2. Reinecker-Bilgram principle [6].

Transformation matrices between the $K_{1 \mathrm{R}}$ and $\mathrm{K}_{2 \mathrm{R}}$ coordinate systems (Fig. 5):

$$
\begin{gathered}
\boldsymbol{M}_{\mathbf{2 R}, \mathbf{1} \boldsymbol{R}}=\boldsymbol{M}_{\mathbf{2} \boldsymbol{R}, \mathbf{2} \boldsymbol{S} \cdot \boldsymbol{M}_{\mathbf{2 S}, \mathbf{1 S}} \cdot \boldsymbol{M}_{\mathbf{1 S}, \mathbf{1} \boldsymbol{R}}} \\
=\left[\begin{array}{cccc}
-\cos \left(\varphi_{1 R}\right) \cdot \sin \left(\varphi_{2 R}\right) & -\cos \left(\varphi_{1 R}\right) \cdot \cos \left(\varphi_{2 R}\right) & \sin \left(\varphi_{1 R}\right) & 0 \\
-\sin \left(\varphi_{1 R}\right) \cdot \sin \left(\varphi_{2 R}\right) & -\sin \left(\varphi_{1 R}\right) \cdot \cos \left(\varphi_{2 R}\right) & -\cos \left(\varphi_{1 R}\right) & 0 \\
\cos \left(\varphi_{2 R}\right) & -\sin \left(\varphi_{2 R}\right) & 0 & 0 \\
0 & 0 & 0 & 1
\end{array}\right]
\end{gathered}
$$

$$
\begin{gathered}
\boldsymbol{M}_{\mathbf{1 R}, \mathbf{2 R}}=\boldsymbol{M}_{\mathbf{1 R}, \mathbf{1} \boldsymbol{S} \cdot \boldsymbol{M}_{\mathbf{1 S}, \mathbf{2} \boldsymbol{S}} \cdot \boldsymbol{M}_{\mathbf{2} \boldsymbol{S}, \mathbf{2 R}}} \\
=\left[\begin{array}{cccc}
-\sin \left(\varphi_{1 R}\right) \cdot \cos \left(\varphi_{2 R}\right) & -\sin \left(\varphi_{1 R}\right) \cdot \sin \left(\varphi_{2 R}\right) & \cos \left(\varphi_{1 R}\right) & 0 \\
-\cos \left(\varphi_{1 R}\right) \cdot \cos \left(\varphi_{2 R}\right) & -\cos \left(\varphi_{1 R}\right) \cdot \sin \left(\varphi_{2 R}\right) & -\sin \left(\varphi_{1 R}\right) & 0 \\
\sin \left(\varphi_{2 R}\right) & -\cos \left(\varphi_{2 R}\right) & 0 & 0 \\
0 & 0 & 0 & 1
\end{array}\right]
\end{gathered}
$$

Taking into consideration the correlation between the velocity vectors of the relative movement in $K_{1 \mathrm{R}}$ and $K_{2 \mathrm{R}}$ coordinate systems [4,9]:

$$
{\overrightarrow{v_{1 R}}}^{(12)}=\boldsymbol{M}_{\mathbf{1} \boldsymbol{R}, \mathbf{2} \boldsymbol{R}} \cdot{\overrightarrow{v_{2 R}}}^{(12)}
$$

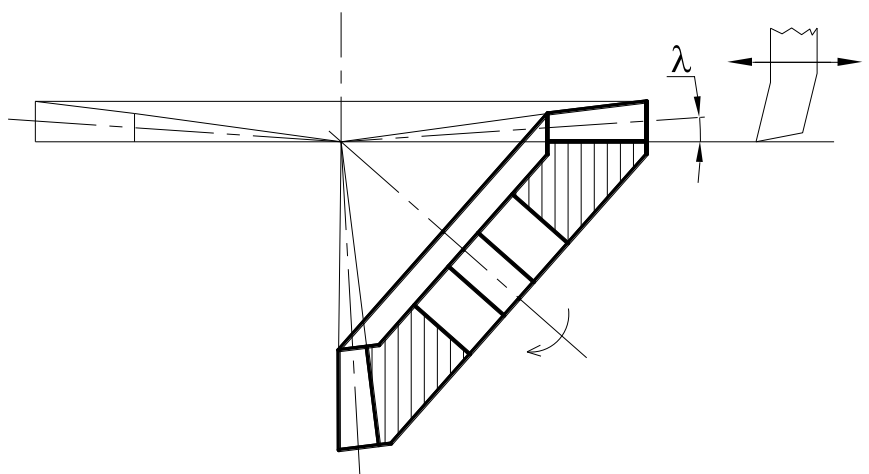

Fig. 3. Heidenreich-Harbeck principle [6].

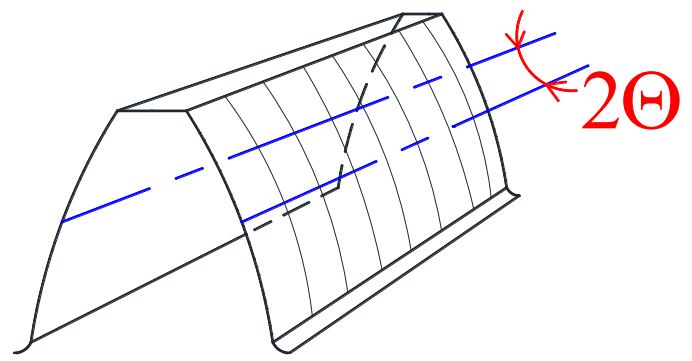

Fig. 4. Definition of planing angle.

in $\mathrm{K}_{1 \mathrm{R}}$ coordinate system, the relative velocity vector, based on (3) is:

$$
{\overrightarrow{v_{1 R}}}^{(12)}=\boldsymbol{M}_{\mathbf{1 R}, 2 \boldsymbol{R}} \cdot \frac{d}{d t}\left(\boldsymbol{M}_{\mathbf{2 R}, \mathbf{1} \boldsymbol{R}}\right) \cdot \overrightarrow{r_{1 R}},
$$

where $\mathrm{P}_{1 \mathrm{k}}$ is the kinematic mapping matrix $[4,9]$ :

$$
\boldsymbol{P}_{1 k}=M_{1 R, 2 R} \cdot \frac{d}{d t}\left(M_{2 R, 1 R}\right)
$$

On the tooth surfaces of the meshing teeth, contact points mutually covering each other can be determined by solving the connection equation - which expresses the 1st Law of Contact - and the vector-scalar function simultaneously $[4,9]$ :

$$
\overrightarrow{n_{1 R}} \cdot{\overrightarrow{v_{1 R}}}^{(12)}=\overrightarrow{n_{2 R}} \cdot{\overrightarrow{v_{2 R}}}^{(12)}=\vec{n} \cdot \vec{v}^{(12)} .
$$

\section{Designing the computer program}

Input data for designing the drive pair are: $m$ module, $z_{1}$ number of teeth of the driver bevel gear wheel, $z_{2}$ number of teeth of the driven gear wheel, $c^{*}$ root clearance factor and the $\alpha_{0}$ angle of contact $[1,3-8]$.

For designing, the necessary geometrical correlations from technical literature was also used, which can be seen below based on Figures 1 and 5 [1,3-8]:

- the largest pitch circle diameters:

$$
d_{01,2}=m \cdot z_{1,2}
$$



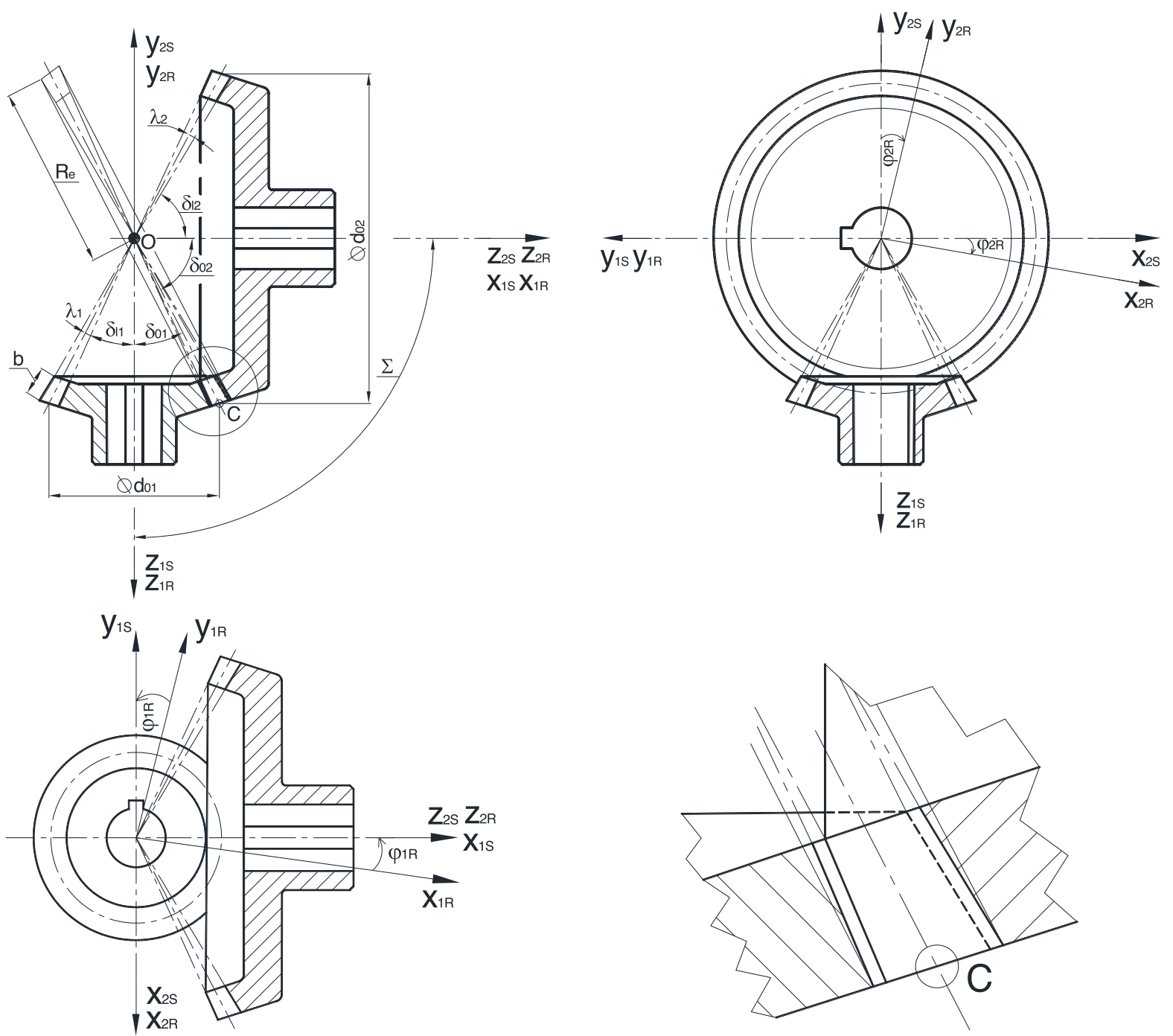

Fig. 5. Connection between the coordinate systems of the bevel gear drive pair.

- half pitch angle of the driver gear wheel:

$$
\delta_{01}=\operatorname{atan}\left(\frac{z_{2}}{z_{1}}\right)
$$

- half pitch angle of the driven gear wheel:

$$
\delta_{02}=90^{\circ}-\delta_{01},
$$

- effective pitch surface radius:

$$
R_{e}=\sqrt{\left(d_{01} / 2\right)^{2}+\left(d_{02} / 2\right)^{2}}
$$

- addendum on the largest diameter:

$$
f_{0}=m,
$$

- dedendum on the largest diameter:

$$
l_{0}=\left(1+c^{*}\right) \cdot m,
$$

- the largest tip circle diameters:

$$
d_{f 1,2}=\left(z_{1,2}+2 \cdot \cos \left(\delta_{01,2}\right)\right) \cdot m,
$$

- the largest root circle diameters:

$$
d_{a 1,2}=z_{1,2} \cdot m-2 \cdot l_{0} \cdot \cos \left(\delta_{01,2}\right),
$$

- face width:

$$
b=\frac{1}{3.5} \cdot R_{e},
$$

- dedendum angle:

- tip cone angles

$$
\lambda=\operatorname{atan}\left(\frac{l_{0}}{R_{e}}\right)
$$

$$
\delta_{f 1,2}=\delta_{01,2}+\lambda,
$$




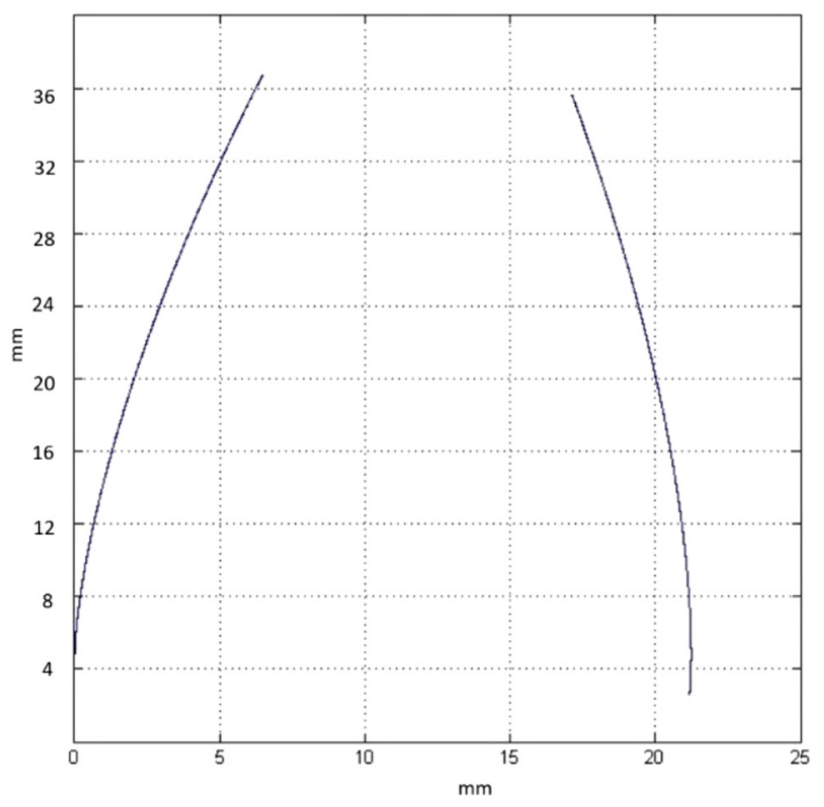

on the smallest diameters

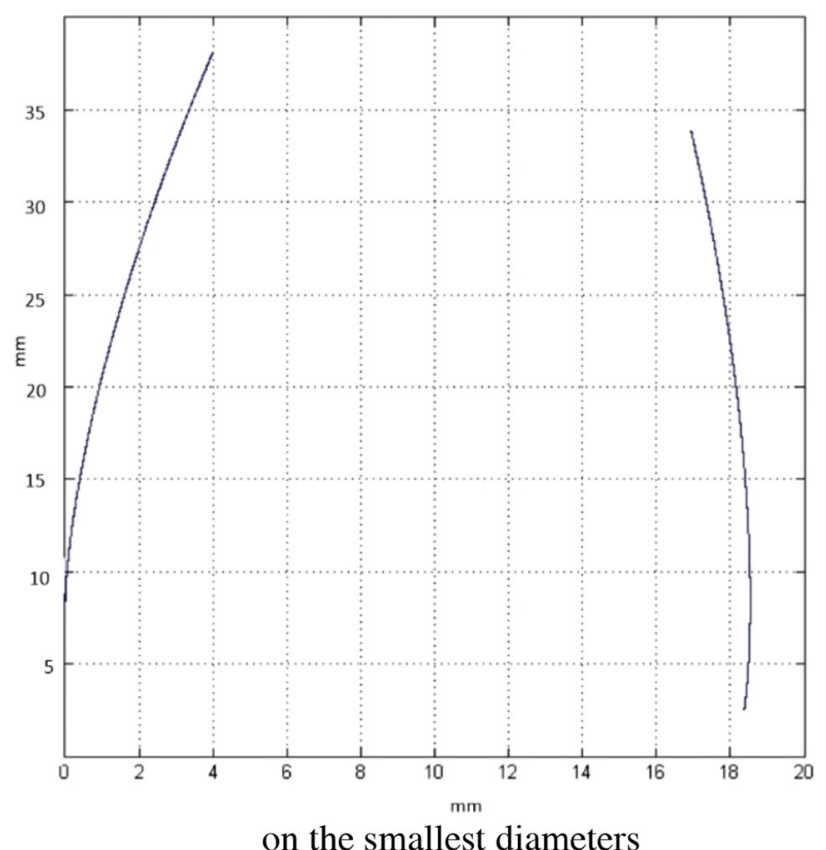

on the smallest diameters

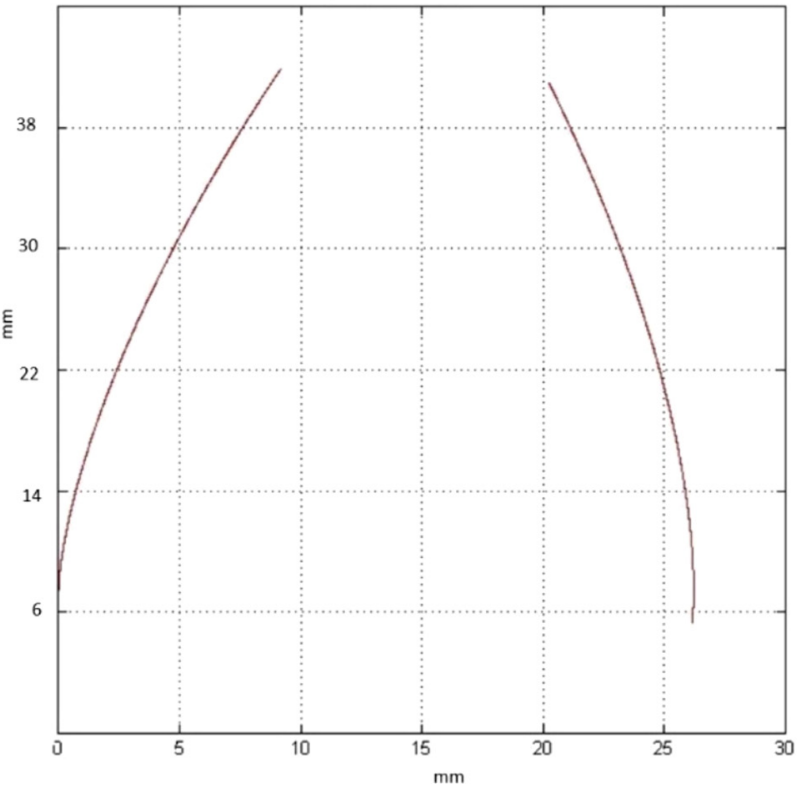

on the largest diameters

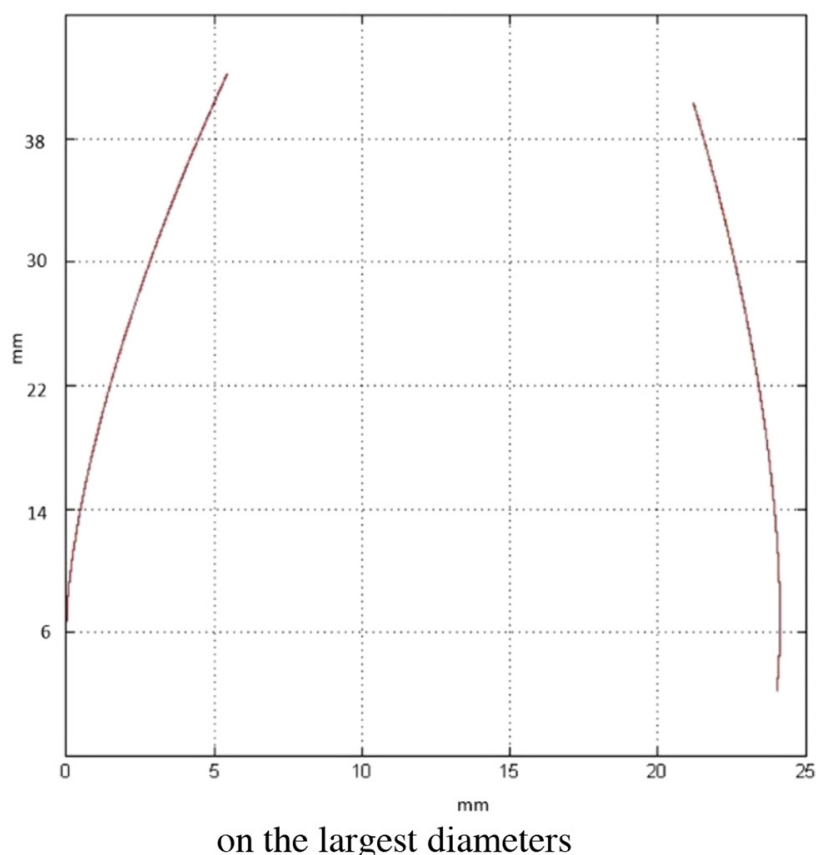

(b)

Fig. 6. Profile curves of the designed bevel gear pair $\left(m=15 \mathrm{~mm}, z_{1}=20, z_{2}=30, \Sigma=90^{\circ}\right)$. (a) Profile curves of the driver gear. (b) Profile curves of the driven gear.

- root cone angles:

$$
\delta_{l 1,2}=\delta_{01,2}-\lambda .
$$

The output of my computer program is some calculated geometrical data of the bevel gear, and the profile curves (Fig. 6) in case of the smallest and largest diameters. Knowing the above mentioned manufacturing technologies
[1,3-8] and the path of the cutting tool this program can determine the shape of the gear profiles.

The program saves the profiles of the bevel gear in .txt file format. Onto the given profile set of dots an interpolating B-spline can be fitted [11]. With the geometrical parameters of the drive pair and its profiles, the CAD model of the bevel gear was made by SolidWorks designing software (Fig. 7). 


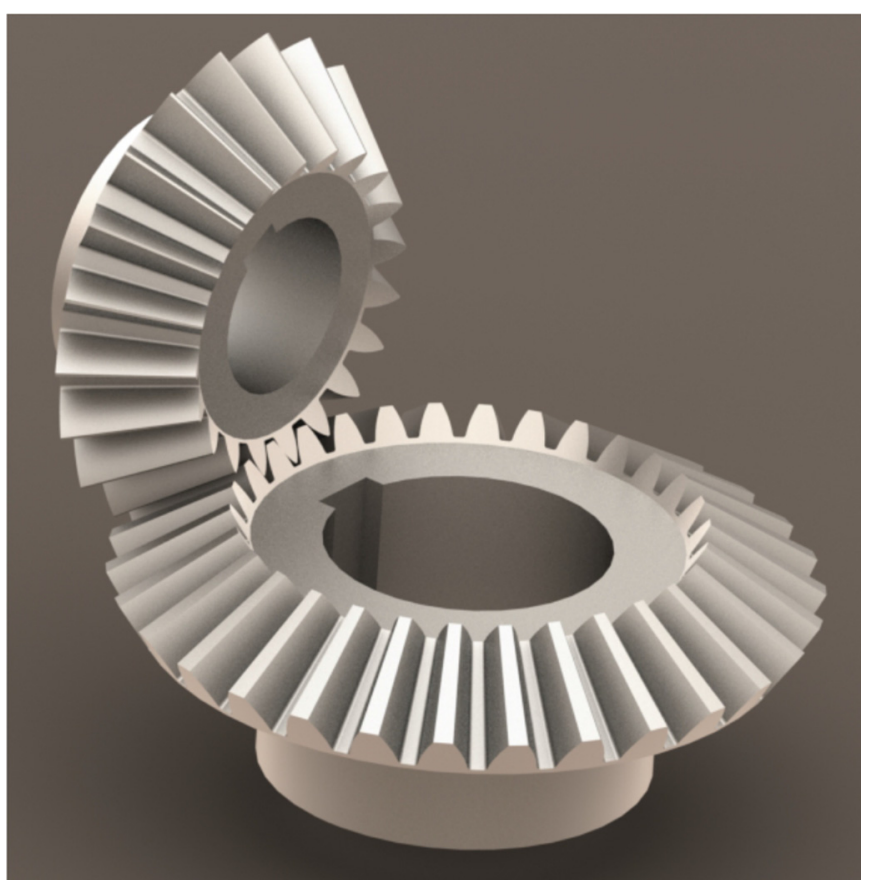

Fig. 7. CAD model of the bevel gear pair having straight teeth $\left(m=15 \mathrm{~mm}, z_{1}=20, z_{2}=30, \Sigma=90^{\circ}\right)$.

Table 1. Parameters of the designed bevel gear pair.

\begin{tabular}{|c|c|c|}
\hline Parameters of the bevel gear pair & Driver gear & Driven gear \\
\hline Module & \multicolumn{2}{|c|}{$m=15 \mathrm{~mm}$} \\
\hline Number of teeth & $z_{1}=20$ & $z_{2}=30$ \\
\hline The largest pitch circle diameters & $d_{01}=300 \mathrm{~mm}$ & $d_{02}=450 \mathrm{~mm}$ \\
\hline Half pitch angle of the pitch circle & $\delta_{01}=56.3^{\circ}$ & $\delta_{02}=33.69^{\circ}$ \\
\hline Effective pitch surface radius & \multicolumn{2}{|c|}{$R_{\mathrm{e}}=270.416 \mathrm{~mm}$} \\
\hline Addendum on the largest diameter & \multicolumn{2}{|c|}{$f_{0}=15 \mathrm{~mm}$} \\
\hline Dedendum on the largest diameter & \multicolumn{2}{|c|}{$l_{0}=18 \mathrm{~mm}$} \\
\hline The largest tip circle diameters & $d_{f 1}=316.64 \mathrm{~mm}$ & $d_{f 2}=474.96 \mathrm{~mm}$ \\
\hline The largest root circle diameters & $d_{a 1}=280.03 \mathrm{~mm}$ & $d_{a 2}=420.04 \mathrm{~mm}$ \\
\hline Face width & \multicolumn{2}{|c|}{$b=77.26 \mathrm{~mm}$} \\
\hline Dedendum angle & \multicolumn{2}{|c|}{$\lambda=3.8^{\circ}$} \\
\hline Tip cone angle & $\delta_{f 1}=60.11^{\circ}$ & $\delta_{f 2}=37.49^{\circ}$ \\
\hline Root cone angle & $\delta_{l 1}=52.5^{\circ}$ & $\delta_{l 2}=29.88^{\circ}$ \\
\hline Circular pitch on the largest pitch circle diameter & \multirow{2}{*}{\multicolumn{2}{|c|}{$\begin{array}{l}t=47.123 \mathrm{~mm} \\
j_{s}=2.356 \mathrm{~mm}\end{array}$}} \\
\hline Clearance at flank & & \\
\hline Pitch circle tooth thickness on the largest diameters & \multicolumn{2}{|c|}{$S_{\mathrm{ax}}=21.2 \mathrm{~mm}$} \\
\hline Transmission & \multicolumn{2}{|c|}{$i=1.5$} \\
\hline
\end{tabular}

\section{LTCA analysis}

The aims of the so called "Loaded Tooth Contact Analysis" (LTCA) are to model the connection of toothed drive pairs and to simulate the model by given loads and boundary conditions. During the LTCA in case of this given geometrical bevel gear (Figs. 6 and 7, Tab. 1) normal stress, normal elastic strain and normal deformation values were analysed on the surface of the driven and driver gear wheels [12-21].

\subsection{Material quality, FE mesh (finite element)}

The property of the material used for our bevel gear is given in Table 2.

During defining the FE mesh in the contact zone, sphere volume $(37 \mathrm{~mm}$ radius) including dense triangles $(1 \mathrm{~mm}$ mesh dimension) has been applied on the toothed area (Fig. 8). Automatic meshing was used on the outside areas. The friction coefficient in the tooth contact zone is $\mu=0.01$, because I considered the liquid and rolling frictions on the contact zone.

\subsection{Loads and boundary conditions}

Four coordinate systems have been defined for LTCAs: $\mathrm{K}_{\mathrm{s}}$ - absolute static, $\mathrm{K}_{\mathrm{s} 1}$-static related to the driver wheel, 
Table 2. Material properties.

\begin{tabular}{ll}
\hline Material quality & Structured steel \\
\hline Density & $7850 \mathrm{~kg} / \mathrm{m}^{3}$ \\
Yield stress & $250 \mathrm{MPa}$ \\
Tensile strength & $460 \mathrm{MPa}$ \\
Poisson factor & 0.3 \\
Young modulus & $200 \mathrm{GPa}$ \\
Temperature & $22{ }^{\circ} \mathrm{C}$ \\
\hline
\end{tabular}

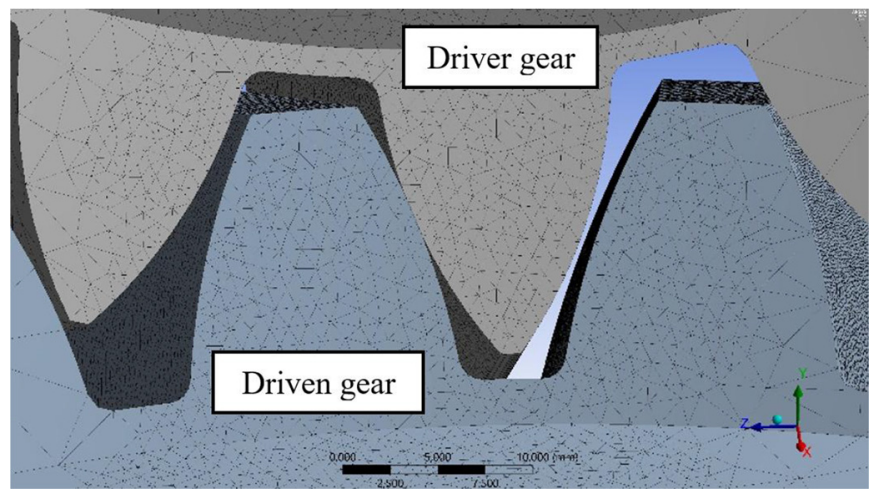

Fig. 8. FE mesh.

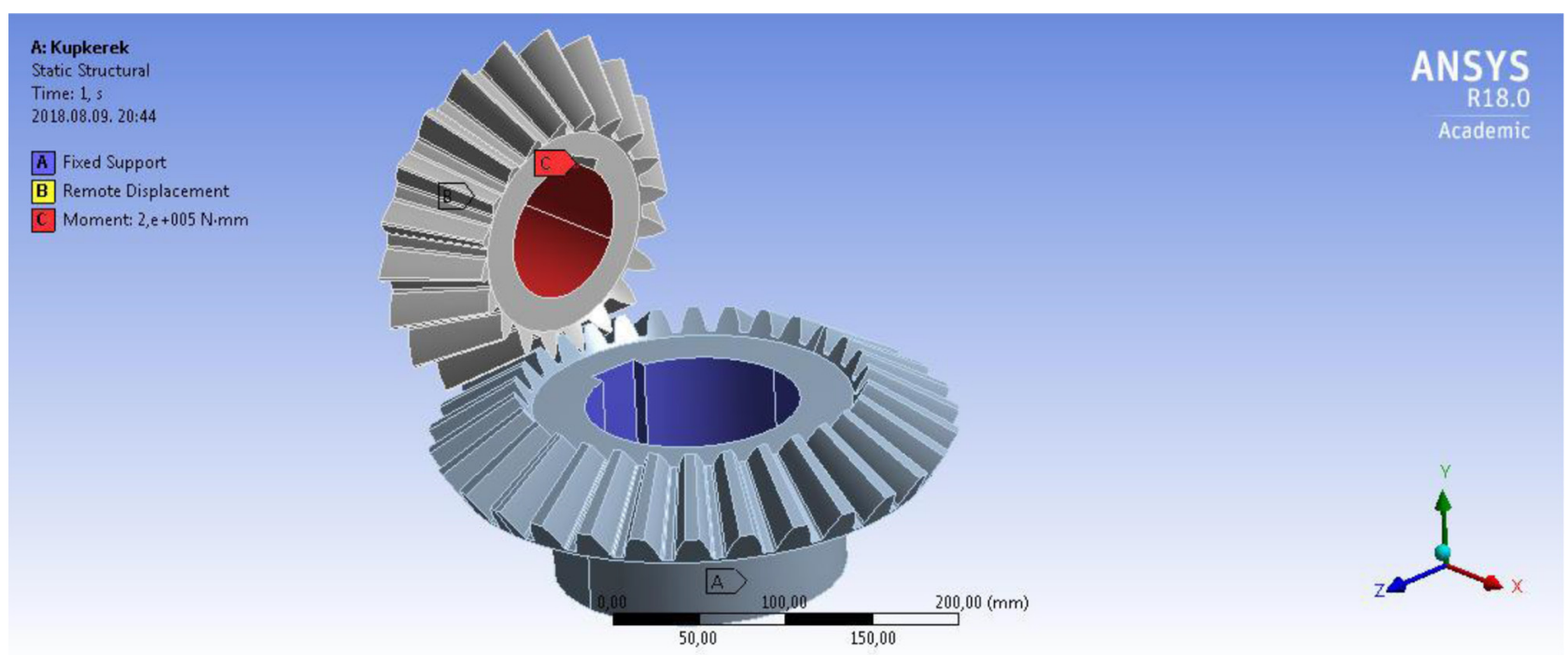

Fig. 9. Setting loads and boundary conditions.

$\mathrm{K}_{\mathrm{s} 2}$-static, related to the driven wheel and $\mathrm{K}_{\mathrm{c}}$ - coordinate system in the tooth contact zone.

During the analyses, the gear having less number of teeth (driver gear) drives the gear having more number of teeth. Five degrees of freedom were fixed of the driver gear, only rotation along the rotational axis was allowed. The driver gear was loaded by $M=200-400 \mathrm{Nm}$ torque by $50 \mathrm{Nm}$ steps. Six degrees of freedom of the driven gear were fixed (Fig. 9).

\subsection{Normal stress analyses}

In a fixed $\mathrm{P}$ point of the body, $\overrightarrow{\rho_{n}}$ signals the stress vector awakening on the $\vec{n}$ normal surface elements. It can be divided into a normal directional component and one perpendicular to it [22-24] (Fig. 10):

$$
\overrightarrow{\rho_{n}}=\sigma_{n} \cdot \vec{n}+\overrightarrow{\tau_{n}},
$$

where the normal stress is [22-24]:

$$
\sigma_{n}=\vec{n} \cdot \overrightarrow{\rho_{n}}
$$

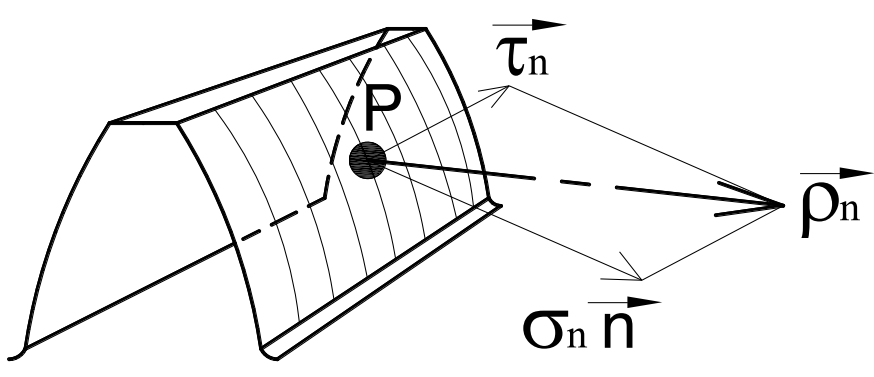

Fig. 10. Defining normal stress.

Normal stress partitions and average normal stress values have been detected as an effect of the different loads, on the tooth surfaces of the driver and driven gear (Fig. 11).

Results are shown in the diagram of Figure 12. In absolute value, as an effect of the increasing load moment, normal stress values also increase on the tooth surfaces of the driver and driven gear. 
The shapes of the two diagrams are the same and they are parallel. The normal stresses of the driven gear are a little higher than the normal stresses of the driver gear in absolute value. Because of the good comparison the same limits were set.

\subsection{Normal elastic strain analyses}

The state of a body's deformation can be signalled by deformation tensor, which can be determined from the displacement vector as seen below [22-24]:

$$
\begin{aligned}
& \boldsymbol{A}=\frac{1}{2}\left(\vec{u}^{\circ} \vec{\nabla}+\overrightarrow{\nabla^{\circ}} \vec{u}\right) \\
& \mathbf{A}=\left[\begin{array}{ccc}
\frac{\partial u}{\partial x} & \frac{1}{2}\left(\frac{\partial u}{\partial y}+\frac{\partial v}{\partial x}\right) & \frac{1}{2}\left(\frac{\partial u}{\partial z}+\frac{\partial w}{\partial x}\right) \\
\frac{1}{2}\left(\frac{\partial v}{\partial x}+\frac{\partial u}{\partial y}\right) & \frac{\partial v}{\partial y} & \frac{1}{2}\left(\frac{\partial v}{\partial z}+\frac{\partial w}{\partial y}\right) \\
\frac{1}{2}\left(\frac{\partial w}{\partial x}+\frac{\partial u}{\partial z}\right) & \frac{1}{2}\left(\frac{\partial w}{\partial y}+\frac{\partial v}{\partial z}\right) & \frac{\partial w}{\partial z}
\end{array}\right]
\end{aligned}
$$
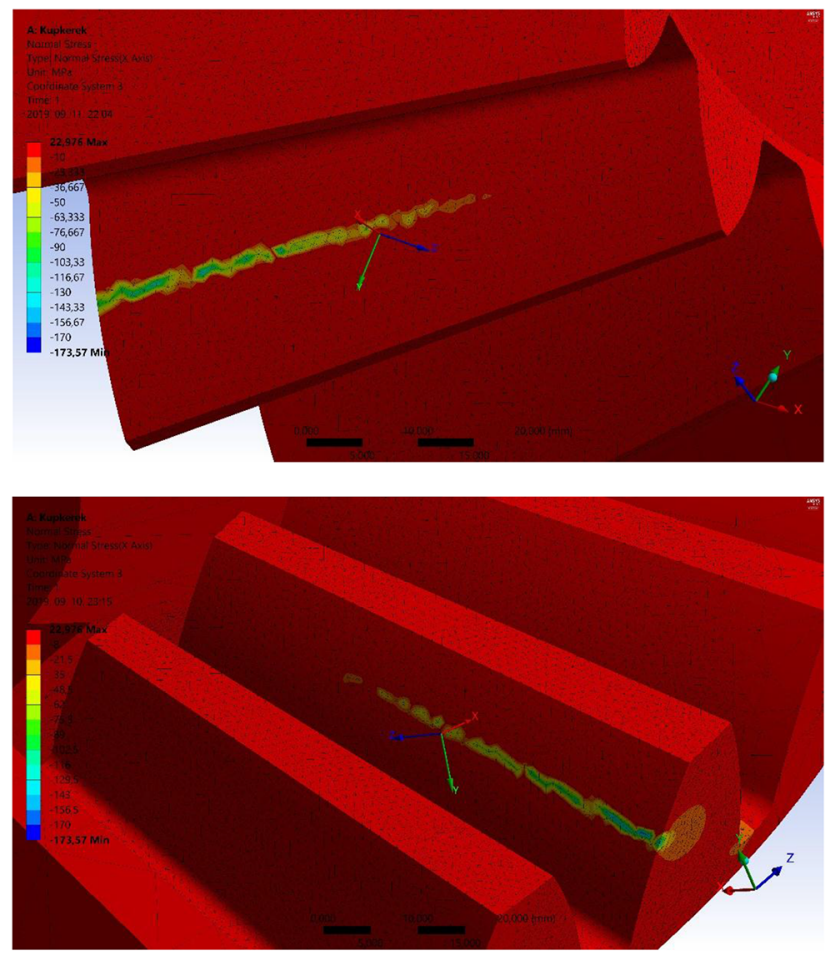

(a) where

$$
\left.\begin{array}{rl}
\varepsilon_{x}=\frac{\partial u}{\partial x} & \gamma_{x y}=\frac{\partial u}{\partial y}+\frac{\partial v}{\partial x} \\
\varepsilon_{y}=\frac{\partial v}{\partial y} & \gamma_{y z}=\frac{\partial v}{\partial z}+\frac{\partial w}{\partial y} \\
\varepsilon_{z}=\frac{\partial w}{\partial z} & \gamma_{z x}=\frac{\partial w}{\partial z}+\frac{\partial u}{\partial x}
\end{array}\right\}
$$

Based on the values of $\varepsilon_{x}, \varepsilon_{y}, \varepsilon_{z}$ elastic strain per unit length and unit vectors related to them, the FE program calculates the normal direction resultant $\left(\varepsilon_{n}\right)$, which is perpendicular to the surface. As an effect of the loads on the surface of the driver and driven gear, normal elastic strain partitions and average normal elastic strain values occur (Fig. 13)

The results are shown in the diagram of Figure 14. You can see that, in absolute value, as an effect of increasing loads, normal elastic strain values also increase on the tooth surfaces of the driver and driven gears.

The shapes of the two diagrams are the same and they are parallel. The normal elastic strains of the driven gear are a little higher than the normal elastic strains of the driver gear in absolute value. Because of the good comparison the same limits were set.
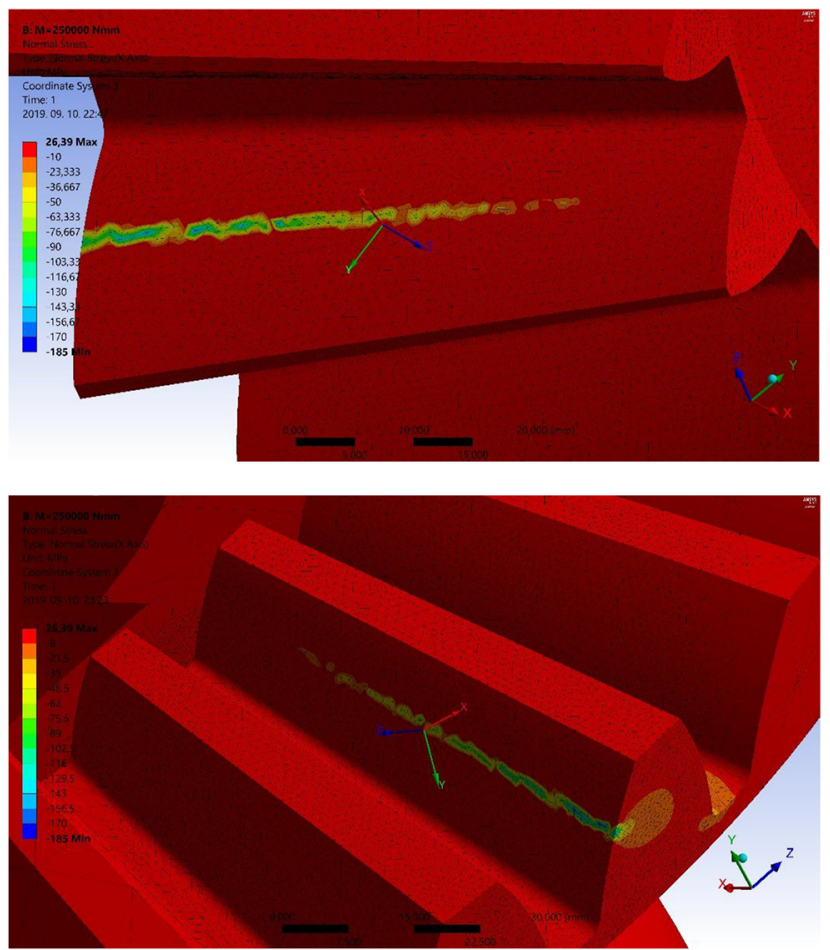

(b)

Fig. 11. Normal stress values. (a) $M=200 \mathrm{Nm}$ : driver gear, $\overline{\sigma_{n}}=-2.054 \mathrm{MPa}$ (top), driven gear, $\overline{\sigma_{n}}=-2.164 \mathrm{MPa}$ (bottom). (b) $M=250 \mathrm{Nm}$ : driver gear, $\overline{\sigma_{n}}=-2.62 \mathrm{MPa}$, driven gear, $\overline{\sigma_{n}}=-2.709 \mathrm{MPa}$. (c) $M=300 \mathrm{Nm}$ : driver gear, $\overline{\sigma_{n}}=-3.203 \mathrm{MPa}$, driven gear, $\overline{\sigma_{n}}=-3.297 \mathrm{MPa}$. (d) $M=350 \mathrm{Nm}$ : driver gear, $\overline{\sigma_{n}}=-3.796 \mathrm{MPa}$, driven gear, $\overline{\sigma_{n}}=-3.893 \mathrm{MPa}$. (e) $M=400 \mathrm{Nm}$ : driver gear, $\overline{\sigma_{n}}=-4.402 \mathrm{MPa}$, driven gear, $\overline{\sigma_{n}}=-4.495 \mathrm{MPa}$. 

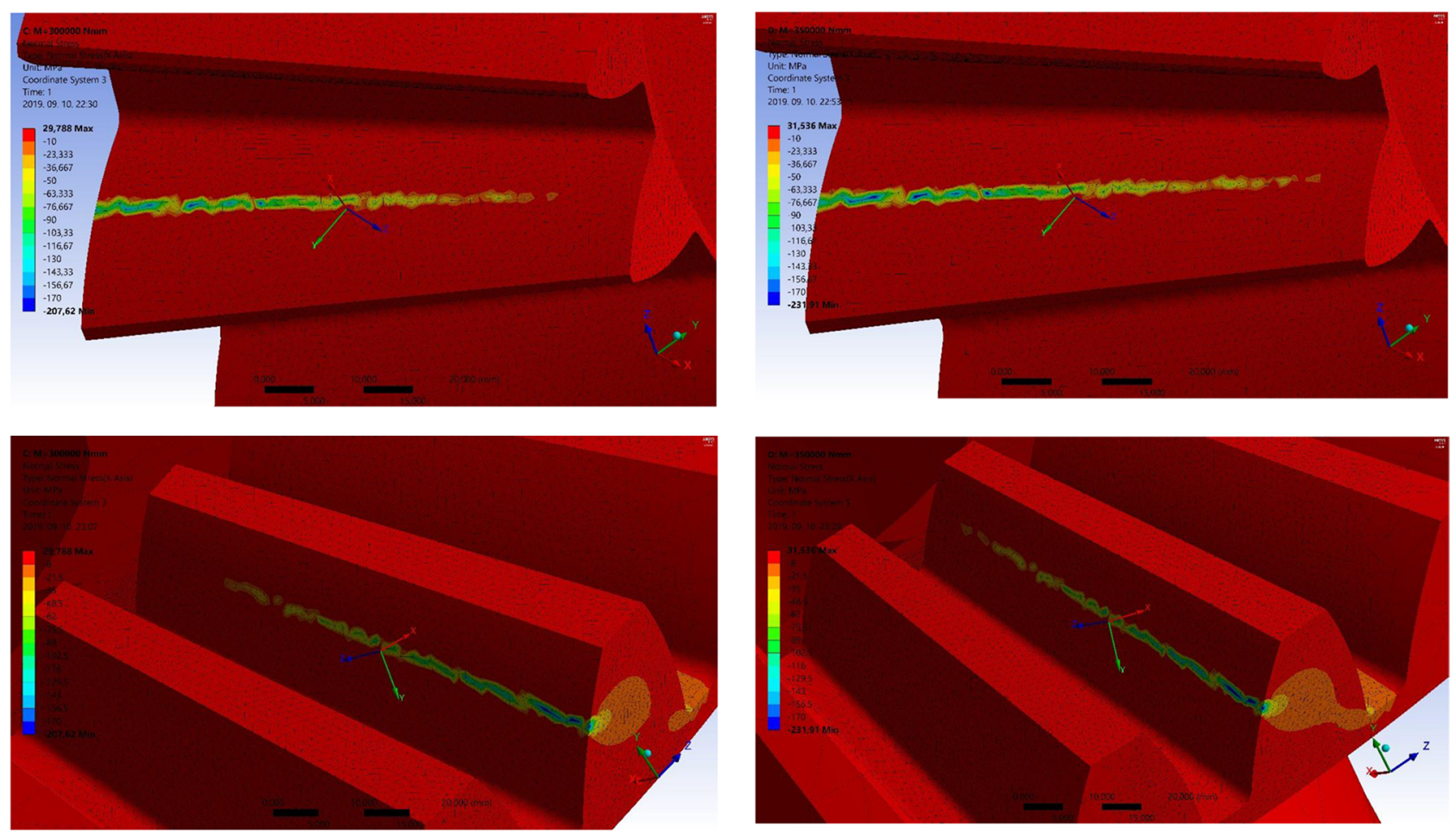

(c)

(d)
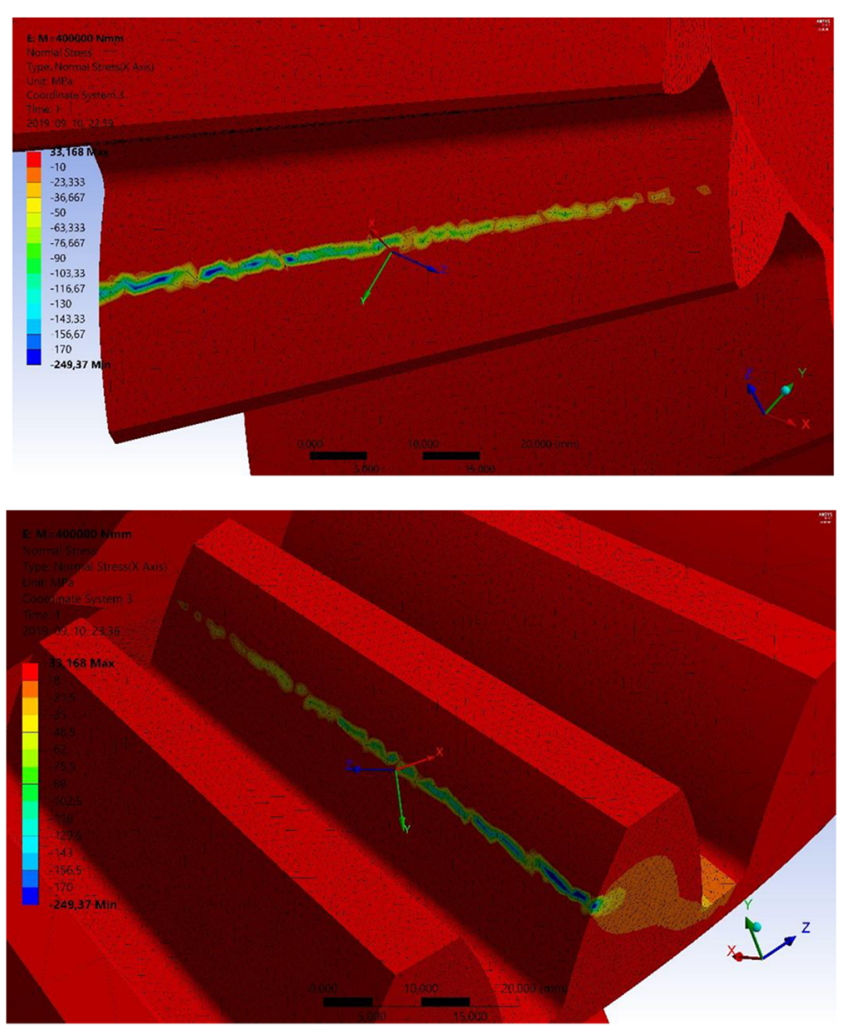

(e)

Fig. 11. Continued. 


\section{Load torque - Normal stress}

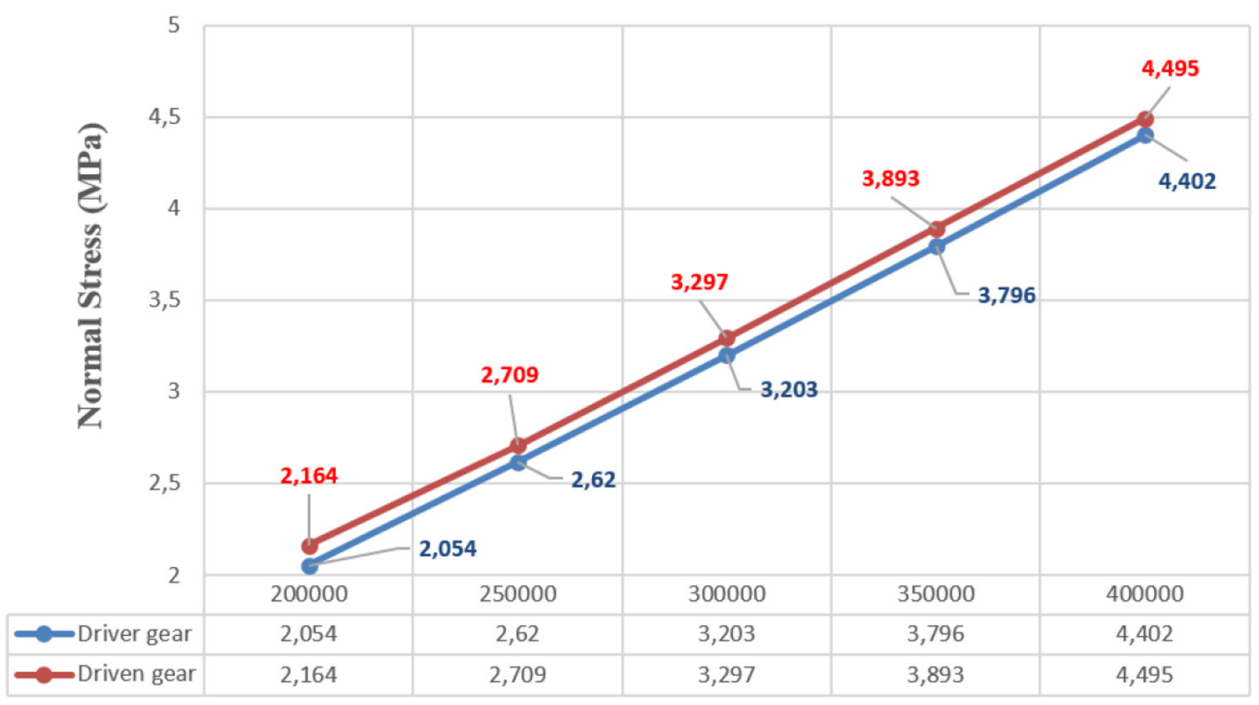

Load torque (Nmm)

Fig. 12. Load - normal stress diagram.
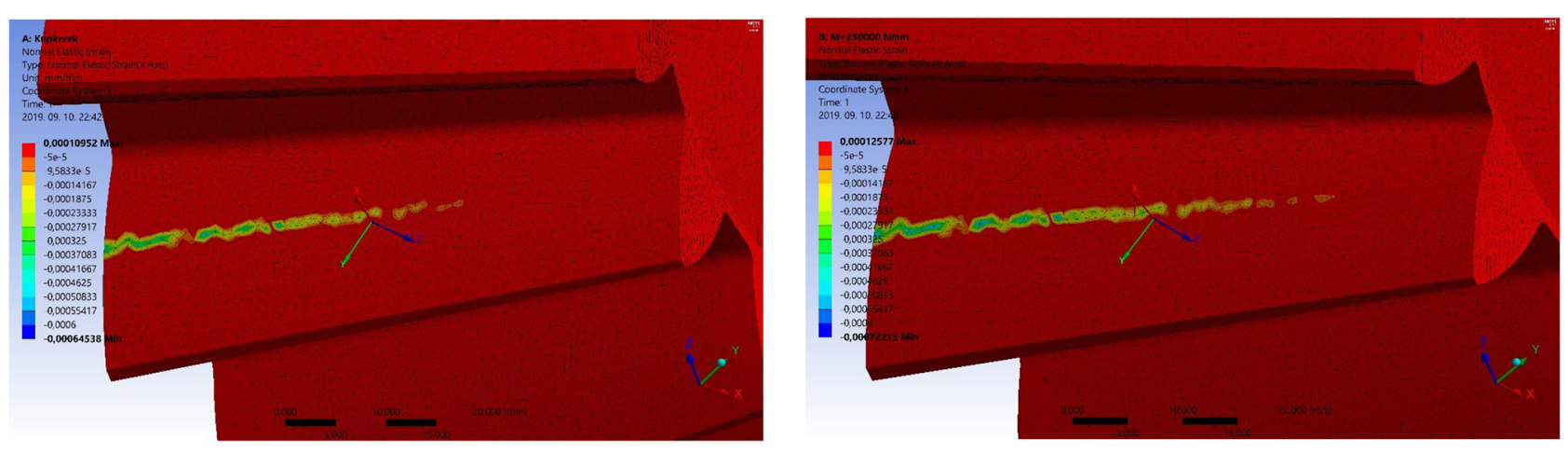

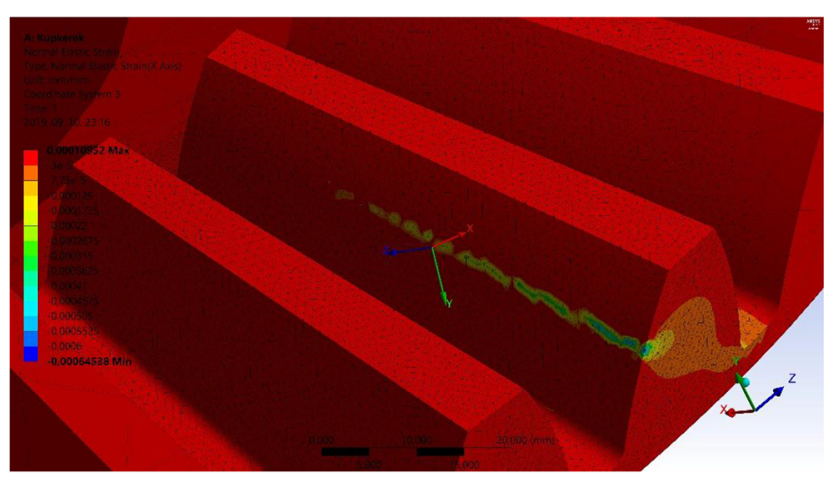

(a)

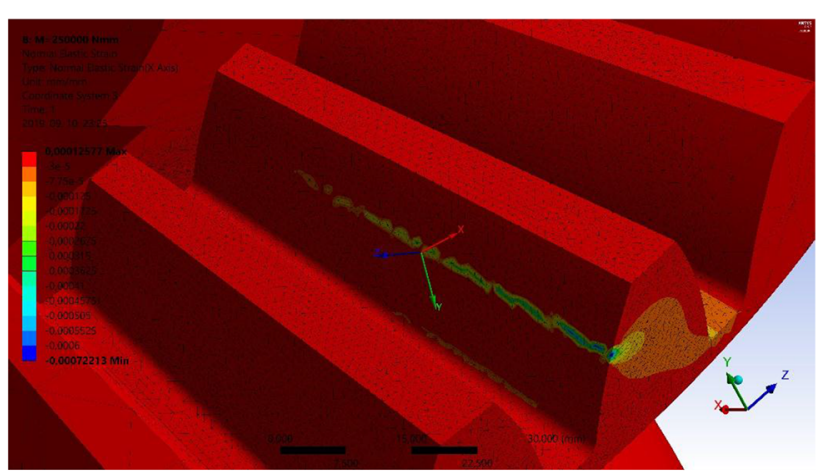

(b)

Fig. 13. Normal elastic strain values as a result of increasing loads. (a) $M=200 \mathrm{Nm}$ : driver gear, $\overline{\varepsilon_{n}}=-0.0000114$ (top), driven gear, $\overline{\varepsilon_{n}}=-0.0000127$ (bottom). (b) $M=250 \mathrm{Nm}$ : driver gear, $\overline{\varepsilon_{n}}=-0.0000141$, driven gear, $\overline{\varepsilon_{n}}=-0.0000154$. (c) $M=300 \mathrm{Nm}$ : driver gear $\overline{\varepsilon_{n}}=-0.0000168$, driven gear, $\overline{\varepsilon_{n}}=-0.0000183$. (d) $M=350 \mathrm{Nm}$ : driver gear, $\overline{\varepsilon_{n}}=-0.0000197$, driven gear, $\overline{\varepsilon_{n}}=-0.0000214$. (e) $M=$ $400 \mathrm{Nm}$ : driver gear, $\overline{\varepsilon_{n}}=-0.0000227$, driven gear, $\overline{\varepsilon_{n}}=-0.0000246$. 

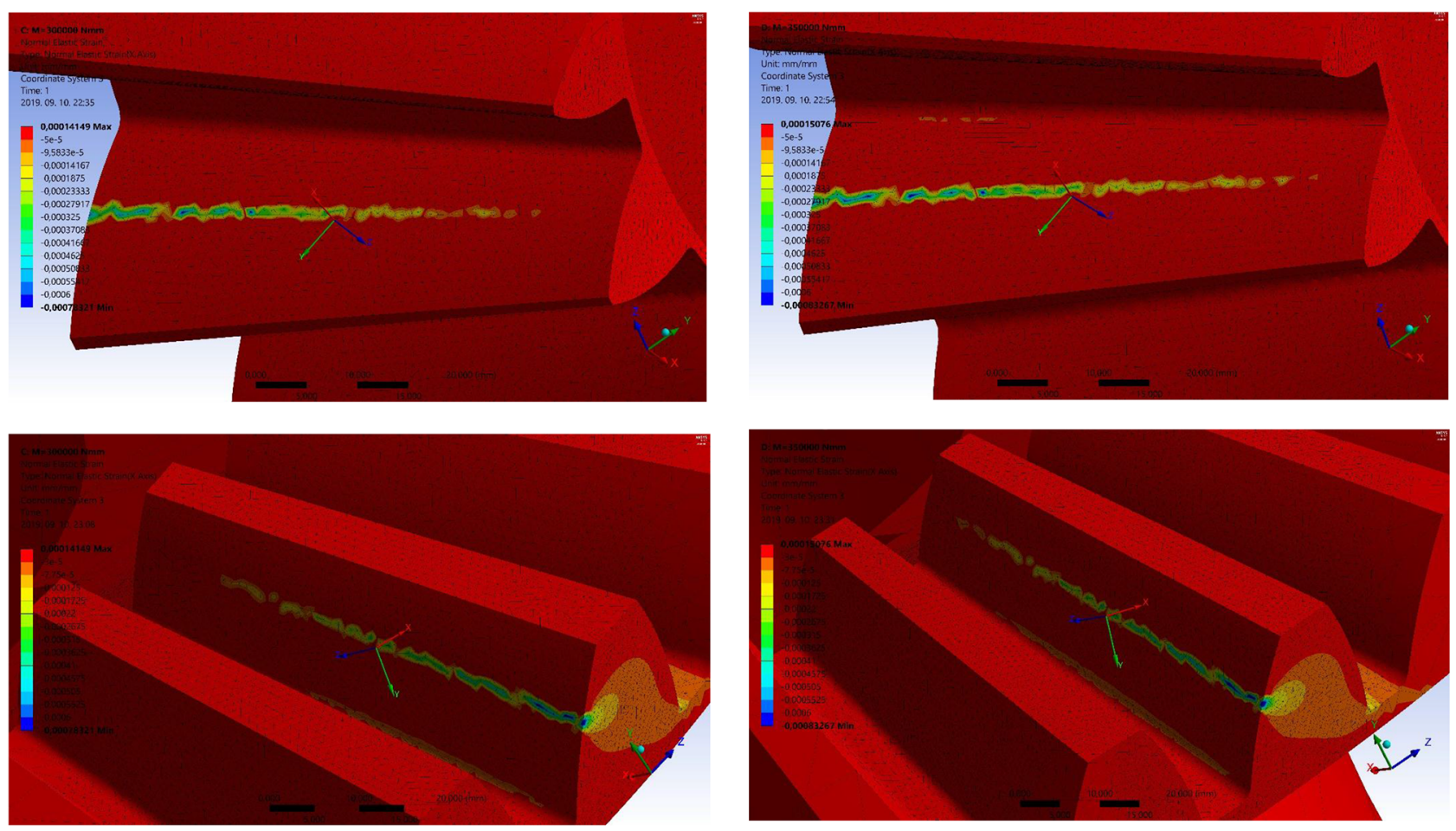

(c)

(d)
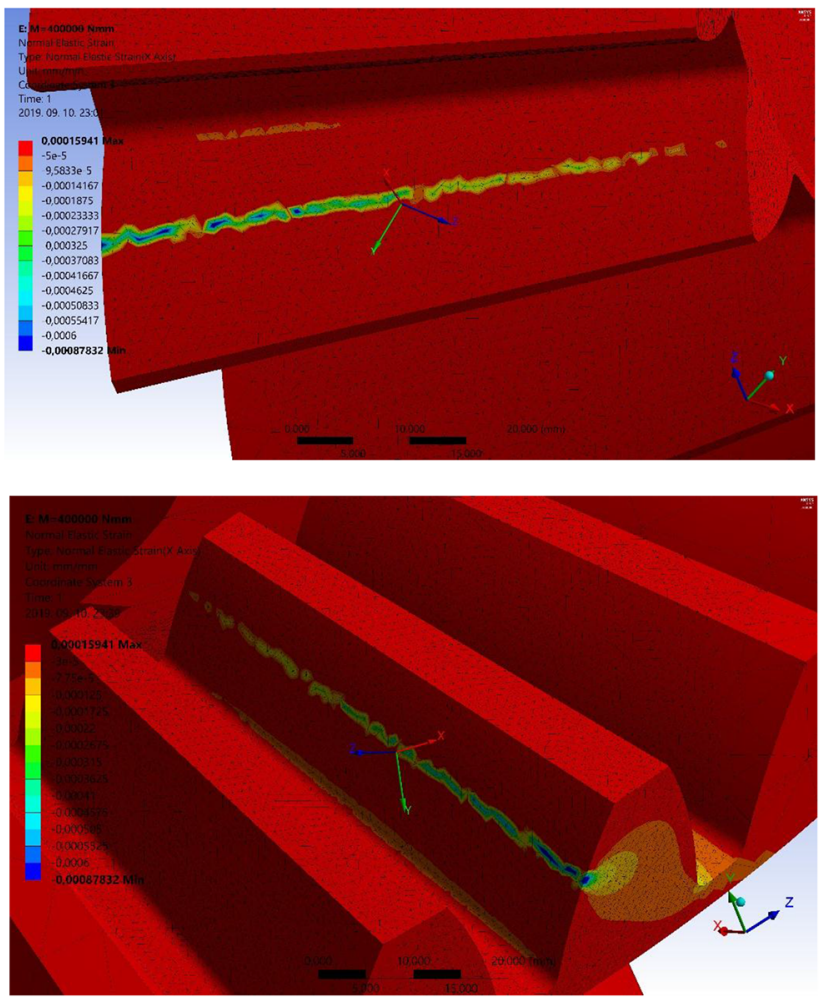

(e)

Fig. 13. Continued. 


\section{Load torque - Normal elastic strain}

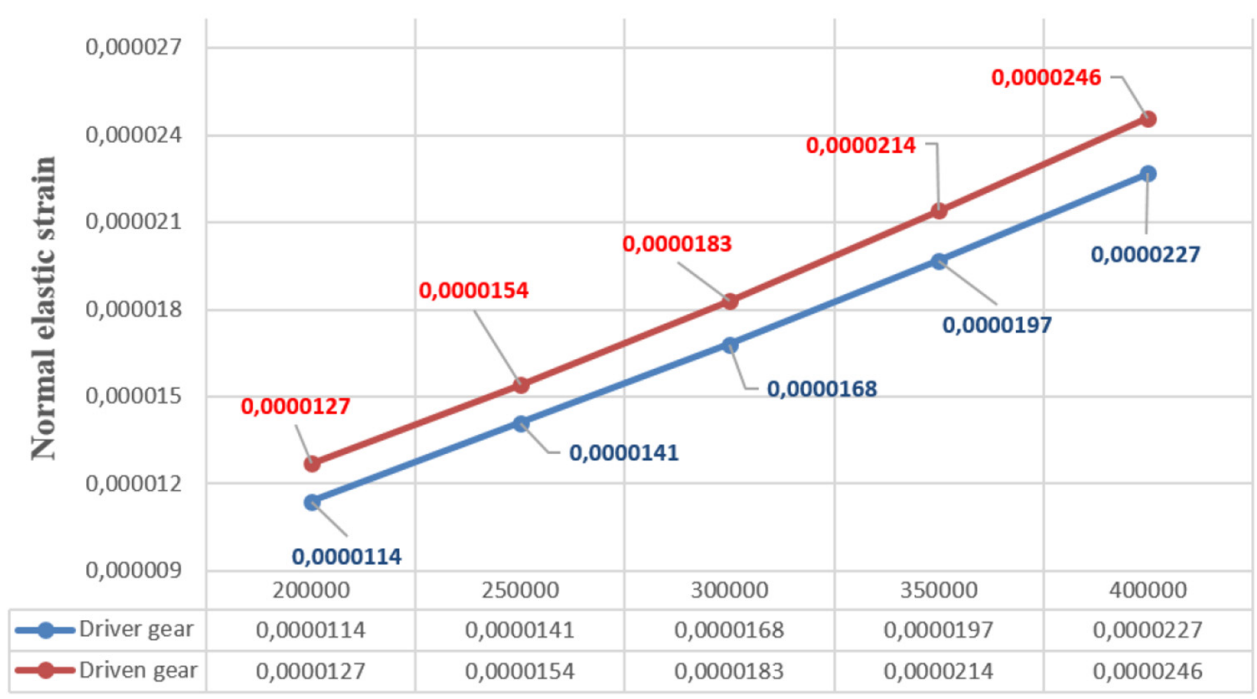

Load torque (Nmm)

Fig. 14. Load - normal elastic strain diagram.

\subsection{Normal deformation analyses}

As an effect of a load, the points of a solid body move, and the beginning state of the body differs from the state after full load application [22-24].

For instance, the position of an arbitrary $\mathrm{P}$ point of the body is given by the following placement vector, in the state before the load was applied [22-24]:

$$
\overrightarrow{r_{P}}=x_{P} \overrightarrow{e_{x}}+y_{P} \overrightarrow{e_{y}}+z_{P} \overrightarrow{e_{z}} .
$$

Signals $\mathrm{P}^{\prime}$ the state of $\mathrm{P}$ point after loading, the related placement vector is $\overrightarrow{r_{P}}$, the displacement vector is $u_{P}$. Based on Figure 15 you can state the following correlations [22-24]:

$$
\overrightarrow{r_{P}^{\prime}}=\overrightarrow{r_{P}}+\overrightarrow{u_{P}}
$$

The displacement vector is the function of the position of the points of the body before loading, i.e. the placement vector [22-24]:

$$
\vec{u}=\vec{u}(\vec{r})
$$

The sum of the displacement vectors related to the points of the body is called displacement field, where the displacement vector is [22-24]:

$$
\vec{u}=u_{x} \overrightarrow{e_{x}}+u_{y} \overrightarrow{e_{y}}+u_{z} \overrightarrow{e_{z}}
$$

The coordinates of the displacement:

$$
\left.\begin{array}{l}
u_{x}=u_{x}(x, y, z) \\
u_{y}=u_{y}(x, y, z) \\
u_{z}=u_{z}(x, y, z)
\end{array}\right\}
$$

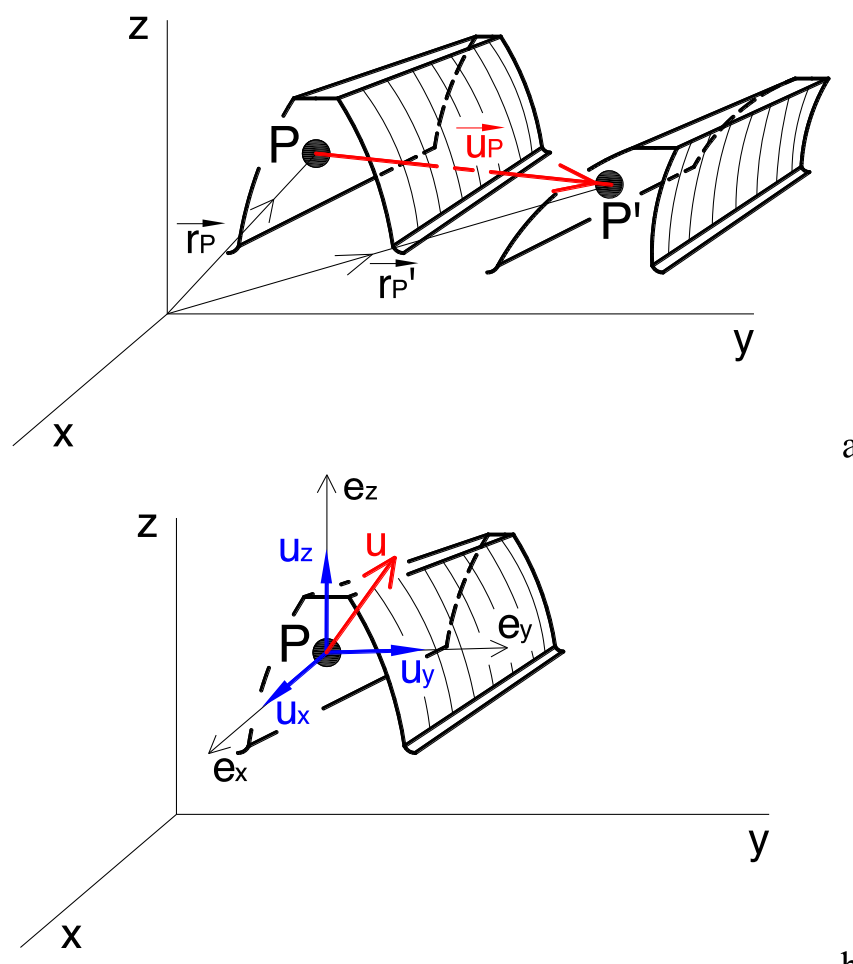

Fig. 15. Definition of displacement vector.

As an effect of the different loads, on the tooth surfaces of the driver and driven gear, the following normal deformation values (in this case $x$ direction deformation) and average normal deformation values (the average of the $x$ direction values) occur (Fig. 16). 
Calculated results are shown in Figure 17. You can see that if the loads are increased the values of normal deformation also increase on the tooth surfaces of the driver and driven gear.

The shapes of the two diagrams are almost parallel. The normal deformations of the driver gear are higher than the normal deformations of the driven gear in absolute value. The teeth are in contact that is why the presages of this specific are different. Because of the good comparison the same limits were set.

\section{Conclusion}

Straight bevel gears are widely used in machinery where the axes of the two shafts intersect, and the faces of the gears themselves form a cone. They are used as load transmission equipment, to change the number of rotation etc. Their further development (from constructional and technological point of view) and their LTCA based on different mechanical properties are highly needed.
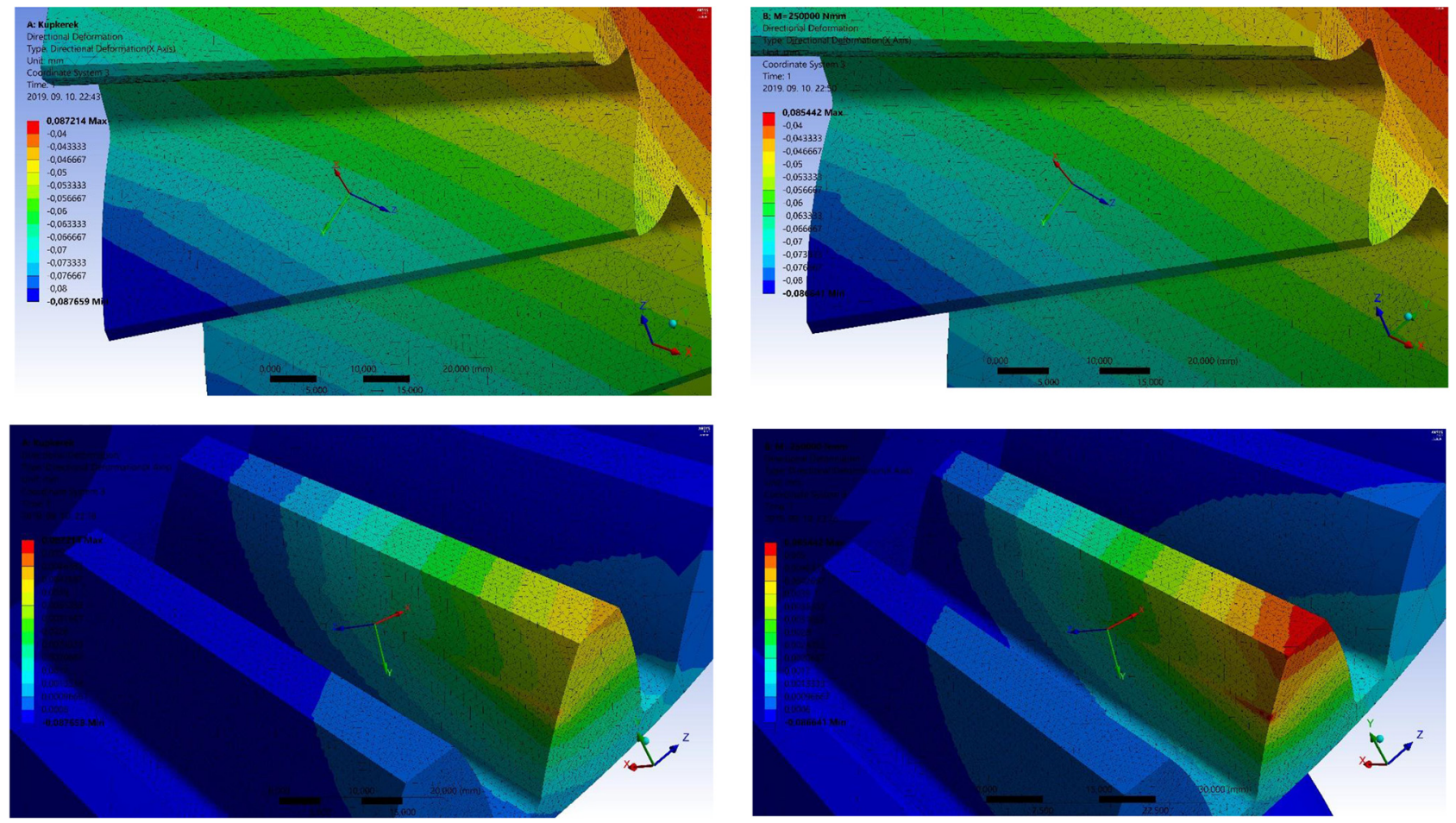

(a)
Based on the geometrical and production analyses of the straight bevel gear pair, I developed a computer program to be able to design the drive pair. This program calculates all the geometrical parameters of the drive pair and draws the profile curves (which occur during production), on the smallest and largest diameters.

The given profile curves can be analyzed from constructional point of view and they are important for making our CAD model.

After that a CAM (Computer-Aided Manufacturing) software can be used to simulate the total production process of the drive pair.

It is important to have the CAD model for LTCA as well. These analyses are good for analyzing the mechanical properties on the driver and driven gear (such as stress, strains, elastic strain). LTCA are also important for having the appropriate constructional planning, to be able to choose the appropriate raw material, and to get important information about loads.

Normal stress, normal deformation and normal elastic strain values have been analyzed on the tooth surfaces of the driver and driven gear pair by different load torques. The results have been averaged, analyzed and shown in diagrams. (b)

Fig. 16. Normal deformation values. (a) $M=200 \mathrm{Nm}$ : driver gear, $\overline{u_{x}}=-0.0654 \mathrm{~mm}$ (top), driven gear, $\overline{u_{x}}=0.00166 \mathrm{~mm}$ (bottom). (b) $M=250 \mathrm{Nm}$ : driver gear, $\overline{u_{x}}=-0.0644 \mathrm{~mm}$, driven gear, $\overline{u_{x}}=0.00207 \mathrm{~mm}$. (c) $M=300 \mathrm{Nm}$ : driver gear, $\overline{u_{x}}=-0.0636 \mathrm{~mm}$, driven gear, $\overline{u_{x}}=0.00247 \mathrm{~mm}$. (d) $M=350 \mathrm{Nm}$ : driver gear, $\overline{u_{x}}=-0.0629 \mathrm{~mm}$, driven gear, $\overline{u_{x}}=0.00286 \mathrm{~mm}$. (e) $M=400 \mathrm{Nm}$ : driver gear, $\overline{u_{x}}=-0.0621 \mathrm{~mm}$, driven gear, $\overline{u_{x}}=0.00325 \mathrm{~mm}$. 

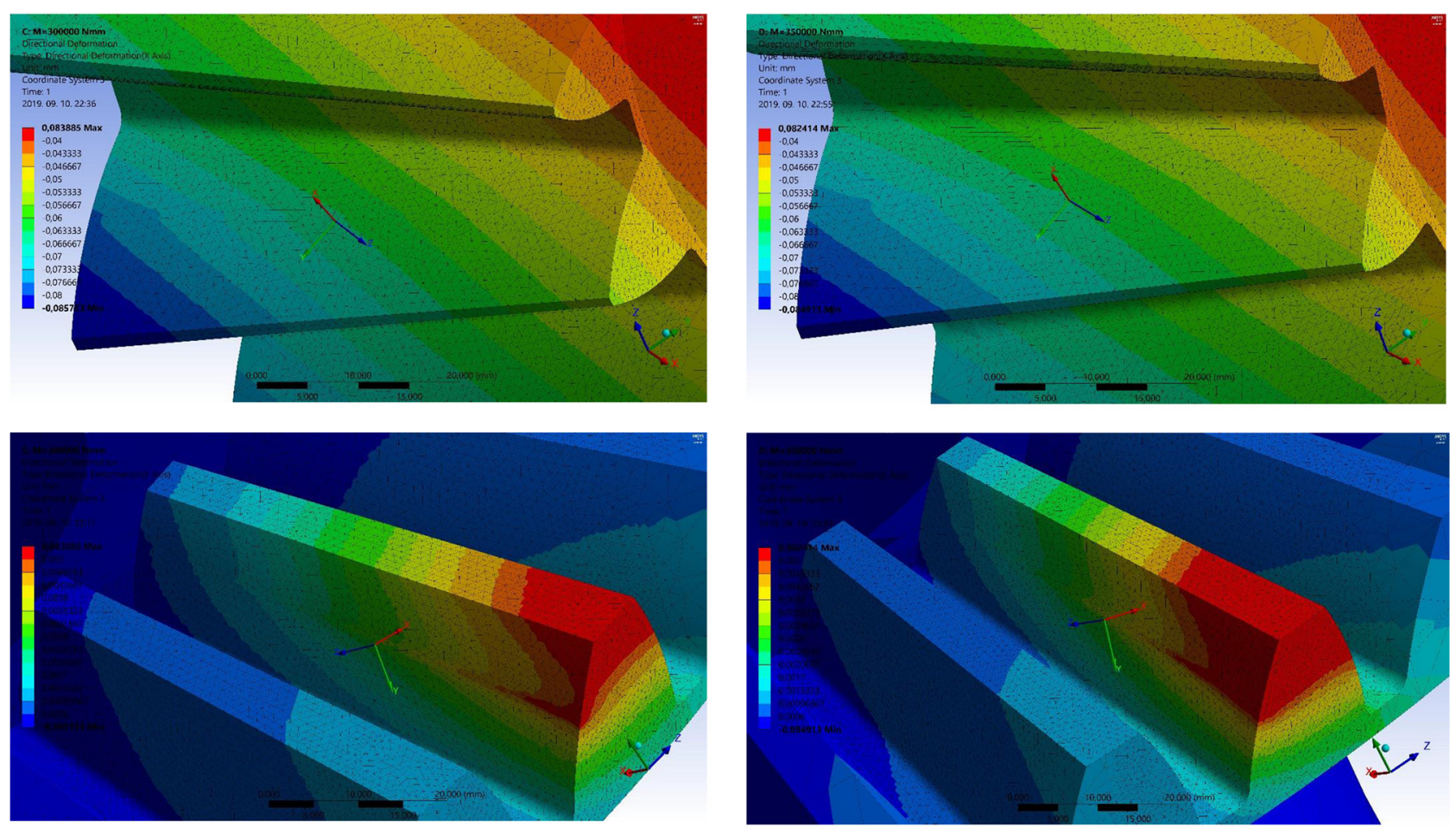

(c)

(d)
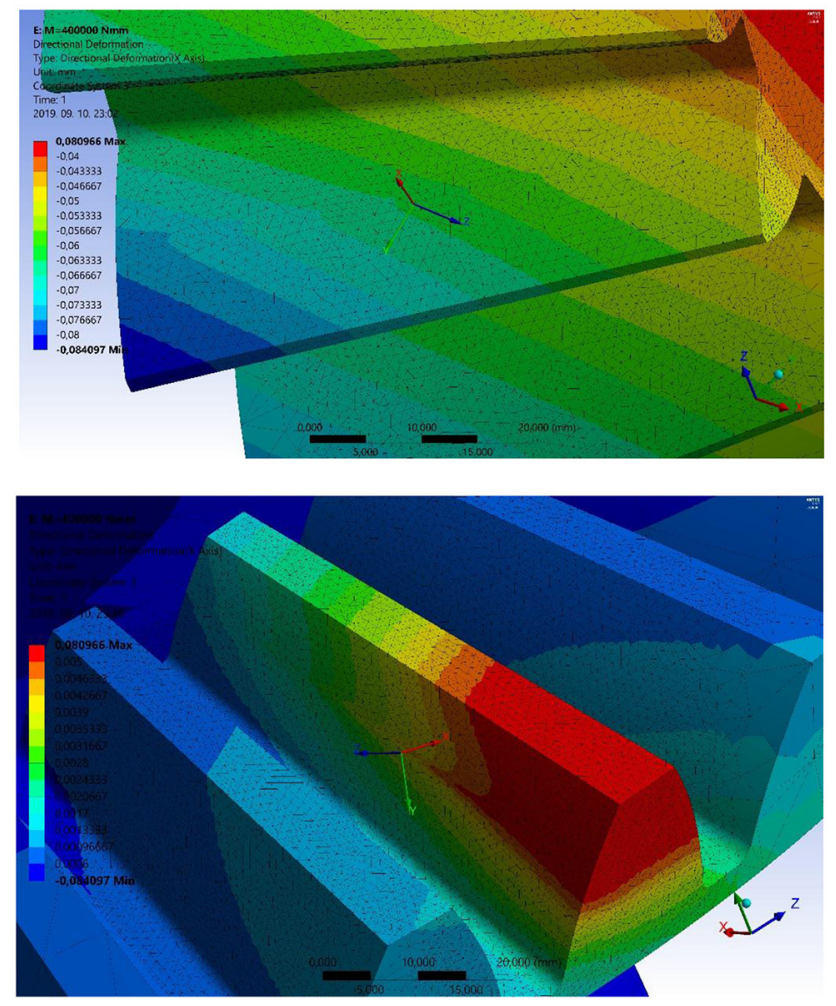

(e)

Fig. 16. Continued. 


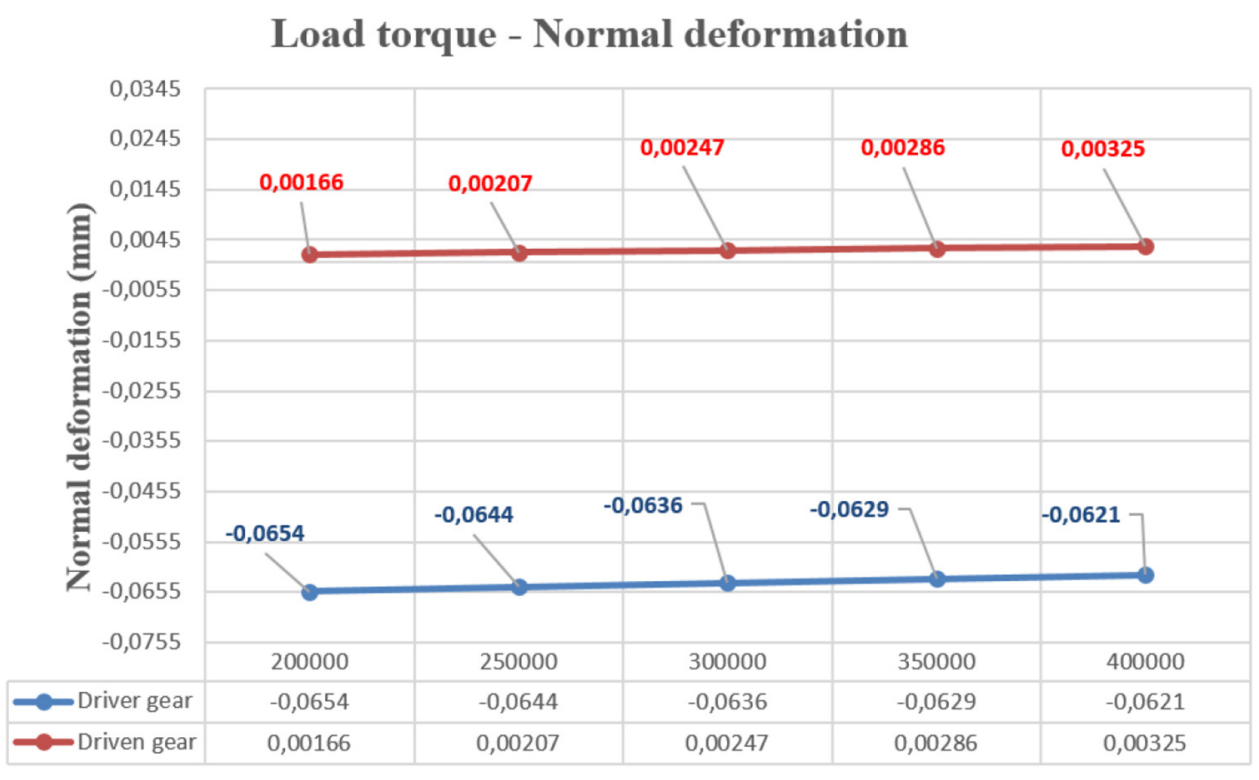

Load torque (Nmm)

Fig. 17. Load-normal deformation diagram.

\section{Nomenclature}

$\vec{v}^{(12)}$
$\overrightarrow{n_{1 R}}$
$\overrightarrow{r_{1 R}}$
$\overrightarrow{r_{2 R}}$
$\overrightarrow{r_{P}}$
$\overrightarrow{\rho_{n}}$
$\overrightarrow{\tau_{n}}$
$\vec{\nabla}$
$M_{2 R, 1 R}, M_{1 R, 2 R}$
$P_{1 k}$
$c^{*}$
$\vec{u}$
$\sigma_{n}$
$2 \cdot \theta$
$A$
$b$
$d_{0}$
$d_{f}$
$d_{1}$
$f_{0}$
$i_{21}, i$
$j_{s}$

Relative velocity vector $\left(\mathrm{mm} / \mathrm{min}^{-1}\right)$ Normal vector of the surface in $K_{1 R}$ coordinate system

Placement vector of the moving points of the profile curve

Placement vector of moving point of conjugated surface

Placement vector

Normal stress vector $(\mathrm{MPa})$

Shear stress vector $(\mathrm{MPa})$

Differential operator

Translation matrices between $\mathrm{K}_{1 \mathrm{R}}$ and $\mathrm{K}_{2 \mathrm{R}}$ coordinate systems

Matrix of kinematic mapping

Root clearance factor

Displacement vector ( $\mathrm{mm})$

Normal stress (MPa)

Angle of planning $\left({ }^{\circ}\right)$

Deformation tensor

Face width $(\mathrm{mm})$

Largest pitch circle diameter $(\mathrm{mm})$

Largest tip circle diameter $(\mathrm{mm})$

Largest root circle diameter $(\mathrm{mm})$

Largest addendum (mm)

Transmission

Clearance at flank $(\mathrm{mm})$
$\mathrm{K}_{1 \mathrm{R}}\left(\mathrm{x}_{1 \mathrm{R}}, \mathrm{y}_{1 \mathrm{R}}, \mathrm{z}_{1 \mathrm{R}}\right) \quad$ Rotational coordinate system related to the driver gear wheel

$\mathrm{K}_{1 \mathrm{~S}}\left(\mathrm{x}_{1 \mathrm{~S}}, \mathrm{y}_{1 \mathrm{~S}}, \mathrm{z}_{1 \mathrm{~S}}\right) \quad$ Static coordinate system related to the driver gear wheel

$\mathrm{K}_{2 \mathrm{R}}\left(\mathrm{x}_{2 \mathrm{R}}, \mathrm{y}_{2 \mathrm{R}}, \mathrm{z}_{2 \mathrm{R}}\right)$ Rotational coordinate system related to the driven gear wheel

$\mathrm{K}_{2 \mathrm{~S}}\left(\mathrm{x}_{2 \mathrm{~S}}, \mathrm{y}_{2 \mathrm{~S}}, \mathrm{z}_{2 \mathrm{~S}}\right) \quad$ Static coordinate system related to the driven gear wheel

Largest dedendum $(\mathrm{mm})$

Module (mm)

Load moment (Nm)

Effective pitch surface radius ( $\mathrm{mm}$ )

Pitch circle face width on the largest diameter $(\mathrm{mm})$

Circular pitch on the largest pitch circle diameter $(\mathrm{mm})$

Number of teeth

Angle of contact $\left(^{\circ}\right)$

Pitch angle $\left(^{\circ}\right)$

Tip cone angle $\left(^{\circ}\right)$

Root cone angle $\left(^{\circ}\right)$

Normal elastic strain ( $\mathrm{mm}$ )

Elastic strain values per unit length (mm)

Dedendum angle $\left(^{\circ}\right)$

Friction coefficient

Shaft angle $\left(^{\circ}\right)$

Addendum angle $\left(^{\circ}\right)$ 


$\begin{array}{ll}\varphi_{1 \mathrm{R}}, \varphi_{2 \mathrm{R}} & \begin{array}{l}\text { Angular displacement }\left(^{\circ}\right) \\ E\end{array} \\ & \begin{array}{l}\text { Distance between the vertex of cones } \\ (\mathrm{mm})\end{array} \\ u, v, w & \text { Coordinates of the displacement } \\ & \text { vector (mm) } \\ \frac{\partial}{\partial x}, \frac{\partial}{\partial y}, \frac{\partial}{\partial z} & \text { Parts of the differential operator } \\ \gamma_{x y}, \gamma_{y x}, \gamma_{\mathrm{xz}} & \text { Shear specific elongation }(\mathrm{mm}) \\ x, y, z & \text { Coordinates }(\mathrm{mm})\end{array}$

This research was supported by the János Bolyai Research Scholarship of the Hungarian Academy of Sciences. The publication itself is partly supported by the EFOP-3.6.1-162016-00022 project, and it is co-financed by the European Union and the European Social Fund.

\section{References}

[1] D.W. Dudley, Gear Handbook, MC Graw Hill Book Co., New York, 1962

[2] R. Gołebski, A. Szarek, Diagnosis of the operational gear wheel wear, Technical Gazette 26, 658-661 (2019)

[3] J. Klingelnberg, Bevel Gear, Fundamentals and Applications, Springer, Berlin, 2016

[4] F.L. Litvin, A. Fuentes, Gear Geometry and Applied Theory, Cambridge University Press, Cambridge, 2004

[5] V. Rohonyi, Fogaskerékhajtások. Múszaki Könyvkiadó, Budapest, 1980

[6] Z. Terplán, Gépelemek IV., Kézirat, Tankönyvkiadó, Budapest, 1975, p. 220

[7] J. Argyris, A. Fuentes, F.L. Litvin, Computerized integrated approach for design and stress analysis of spiral bevel gears, Comput. Methods Appl. Mech. Eng. 191, 1057-1095 (2002)

[8] I. Popa-Müller, Generation of eloid bevel-gear on toothcutting machine with the generating face-gear, 15th International Conference in Mechanical Engeneering, ClujNapoca, 2007

[9] F.L. Litvin, Gear geometry and applied theory, Prentice Hall, Englewood Cliffs, NJ, 1994

[10] A. Fuentes, J.L. Iserte, I. Gonzalez-Perez, F.T. SanchezMarin, Computerized design of advanced straight and skew bevel gears produced by precision forging, Comput. Methods Appl. Mech. Eng. 200, 2363-2377 (2011)
[11] I. Juhász, Görbékés felületek modellezése, Miskolci Egyetem, elektronikus jegyzet, p. 114

[12] Z. Fangyan, Z. Mingde, Z. Weiqing, T. Rulong, G. Xiaodong, On the deformed tooth contact analysis for forged bevel gear modification, Mech. Mach. Theory 135, 192-207 (2019)

[13] G.D. Bibel, A. Kumar, S. Reddy, R. Handschuh, Contact stress analysis of spiral bevel gears using finite element analysis, J. Mech. Des 117, 235-240 (1995)

[14] F.L. Litvin, A. Fuentes, I. Gonzales-Perez, L. Carnevali, T.M. Sep, New version of Novikov-Wildhaber helical gears: computerized design, simulation of meshing and stress analysis, Comput. Methods Appl. Mech. Eng. 191, 5707$5740(2002)$

[15] F.L. Litvin, A. Fuentes, I. Gonzalez-Perez, L. Carvenali, K. Kawasaki, R.F. Handschuh, Modified involute helical gears: computerized design, simulation of meshing and stress analysis, Comput. Methods Appl. Mech. Eng. 192, 3619 3655 (2003)

[16] S. Peng, H. Ding, G. Zhang, J. Tang, Y. Tang, New determination to loaded transmission error of the spiral bevel gear considering multiple elastic deformation evaluations under different bearing supports, Mech. Mach. Theory 137, 37-52 (2019)

[17] I. Popa-Müller, Case-study and simulation by meshing of bevel-gears, 14th International Conference in Mechanical Engeneering, Tg-Mures, 2006

[18] I. Popa-Müller, Simulation of Generation by Meshing of Conical Gear Octoid II with Hobbing Machine HeidenreichHarbeck, 18th International Conference in Mechanical Engeneering, Baia Mare, 2010

[19] J.K. Theodore, Tooth contact analysis of spiral bevel and hypoid gears under load, SAE Trans. 90, 2205-2216 (1981)

[20] H. Zehua, D. Han, P. Shandong, T. Yi, T. Jinyuan, Numerical determination to loaded tooth contact performances in consideration of misalignment for the spiral bevel gears, Mech. Mach. Theory 151, 343-355 (2019)

[21] W. Wagner, S. Schumann, B. Schlecht, Co-simulation of the Tooth Contact of Bevel Gears within a Multibody Simulation, Forsch Ingenieurwes 83, 425-433 (2019)

[22] I. Kozák, Gy. Szeidl, Fejezetek a szilárdságtanból, Kézirat, 2008-2012, Miskolci Egyetem, p. 284. elektronikus jegyzet

[23] S. Moaveni, Finite Element Analysis, Theory and Application with ANSYS, Pearson Education Limited, London, 2015, p. 928

[24] I. Páczelt, T. Szabó, A. Baksa, A végeselem módszer alapjai, Miskolci Egyetem, p. 243

Cite this article as: S. Bodzás, Computer-aided design and loaded tooth contact analyses of bevel gear pair having straight teeth by different loaded torques, Mechanics \& Industry 21, 109 (2020) 
(c) 2019. Notwithstanding the ProQuest Terms and conditions, you may use this content in accordance with the associated terms available at .

https://www.mechanics-industry.org/articles/

eca/full_html/2020/01/mi190163/mi190163.html 